\title{
Evaluation of hydration status and fluid intake among low risk postpartum women in local community delivered in Hospital Ampang.
}

Nur Zaireena Zainal ( $\nabla$ drzaireen@usim.edu.my )

Universiti Sains Islam Malaysia - Kampus Pandan Indah https://orcid.org/0000-0001-7297-3125

Nadeeya Ayn' Umaisara Mohamad Nor

Universiti Sains Islam Malaysia

Mohd Ikmal Hakim Mohd Azman

Universiti Sains Islam Malaysia

Nur Amirah Al Husna Zainudin

Universiti Sains Islam Malaysia

Siti Sarah Mustapa

Ampang Hospital, Malaysia

Rasyidah Mohamed

Ampang Hospital, Malaysia

Muralitharan Ganesalingam

Ampang Hospital, Malaysia

Rafidah Hanim Mokhtar

universiti Sains Islam Malaysia

Research article

Keywords: dehydration, hydration status, plasma osmolality, postpartum, thromboembolism

Posted Date: July 16th, 2020

DOI: https://doi.org/10.21203/rs.3.rs-41848/v1

License: (1) This work is licensed under a Creative Commons Attribution 4.0 International License.

Read Full License 


\section{Abstract}

Background: Adequate fluid intake is very crucial for mothers during postpartum as any dehydration that ensues during this period may predispose them to the risk of developing venous thromboembolism event. Yet, the sociocultural influences may have deterred some of them from adequate fluid intake especially those from Asian region. This study aims to determine hydration status of low risk postpartum women during postpartum period among Malaysian women.

Methods: A prospective observationalstudy involving assessment of hydrational status at 3 points; after 24 hours, at the 3 rd week and at the 6 th week postpartum was conducted. Apart from hydrational status where patients were requested to recordon weekly basis of their input and output fluid intake in a diary, they also underwent a series of biochemical parameters assessment.

Results: 56 patients met the inclusion criteria. The sociodemographic data were analysed decriptively whereby all in the patients were in reproductive age group, with mean (SD) age of 27.96 (4.46) years. The majority were of Malay ethnicity $94.6 \%$ and $66.1 \%$ were multiparous. As many as $92 \%$ of them had at least secondary level of education and more than half were employed (55.4\%). Subsequent analysis $(n=15)$ at 3rd and 6th week following womenwho had completed all 3 follow ups showed; statistically significant evidence of underhydration from the biochemical test results. Repeated analysisat the 3rd week and 6th week revealed that there were significant differences using Friedman test in levels of urea $\left(p=0.001^{b}\right)$, creatinine $\left(0.008^{b}\right)$, as well as plasma osmolality $\left(p<0.001^{b}\right)$. Similarly with urine specific gravity $(p=0.002)$ and urine osmolality $\left(0.002^{a}\right)$ calculated with repeated measures ANOVA from baseline. This correlated with the overall lack offluid intake taken by patients which recorded $1.78 \mathrm{~L} /$ day at 3 rd week and $2.13 \mathrm{~L} /$ day by 6 th week, values which were lower than recommended amount for nursing mother.

Conclusion: The results suggested that lower fluid intake among low risk postpartum women during the postpartum period may predisposes risk of venous thromboembolism. Emphasizing adequate amount of fluid intake among low risk post partum women is crucial and will reduce possible risk of venous thromboembolism.

\section{Background}

Pregnancy is a hypercoagulable state where all three factors in Virchow's triad apply which include hypercoagulability, venous stasis and vascular damage. Although this state is a physiological process in pregnancy, it poses higher risk in some patients to thromboembolic events. The awareness of the risk thromboembolism and efforts in preventing it during antenatal and postpartum is increasing in the recent years. The United Kingdom maternal and mortality rate due to thromboembolism was 0.79 in 100 thousand livebirths ( $n=18 / 155 ; 11.6 \%)$ between the year 2006- 2008 (Lewis, 2011). Our local data revealed higher incidents with 1.5 in 100 thousand livebirths in $2007(n=7 / 136 ; 5.1 \%)$. The cases 
increased to 4.7/100K livebirths in the year 2008 ( $n=23 / 133 ; 17.3 \%$ ) (Krishnan, n.d.). Studies had also shown that incidences were 5 times higher during puerperium as compared to during pregnancy and up to 60 times higher as compared to a non pregnant woman. This is especially so, in first three weeks of postpartum. (Reducing the Risk of Venous Thromboembolism during Pregnancy and the Puerperium, 2015) (POMP et al., 2008) (Heit et al., 2005).Many studies contributed to the formation of guidelines to further improve antenatal and post natal care. Unfortunately the existing risk scoring and screening emphasize only on patients with a known higher risk to develop venous thrombosis event (VTE). These patients receive the package of propercounseling, education tools and are started on anticoagulant with frequent monitoring. On the other hand, the lower risk group does not receive equal attention where their hydrational status and mobilization during their post-partum period are never objectively assessed. This is the window period which we may have missed as higher incidences of VTE happens within 6 weeks postpartum and up to 3 months(POMP et al., 2008) (Heit et al., 2005) (Kamel et al., 2014). This is also especially important in a society that has practices that affect both hydration as well as mobilization of a mother in her confinement period.

Most of Malaysian mothers were taken care by the senior family members according to their cultural practices during the 'confinement' or lying-in period post delivery. Although this cultural practice undoubtly provide good emotional and physical support, in various Asian cultures, there aresome similarities in terms of the caregivers limiting the mothers'types of food and fluids they may consume. These various cultural practices are also similar where most women will be advised to almost completely lie at home with restricted movements (Koon et al., 2005).Some extreme practices even for bid the women from washing their hair and taking bath because the culture believe that the mother needed to be kept warm to expedite the healing process(Koon et al., 2005). Unfortunately these of course exposes the women to risk of sepsis as lack of hygiene. Studies has revealed that higher risk of VTE occurs during the first few weeks, especially first to 3rd week of post partum, partly contributed by immobility and postnatal infections(Abdul Sultan et al., 2014).The culture may actually predisposing the mothers to the higher risk of developing VTE despite being a lower risk group.

Although many studies and guidelines emphasize on adequate fluid intake during the postpartum period(Koon et al., 2005) (Krishnan, n.d.) there were no exact amount mentioned and written clearly to the patients or in the thrombosis guidelines. Furthermore, there were very few published studies on the fluid intake and hydration status of postpartum women in specifically among our Malaysian mothers adhering to the local customs. Unfortunately there is also not one single index of measurement able to accurately measure the amount of body fluid(Armstrong et al., 2012) (Armstrong et al., 2013). This is because the process of water homeostasis is very dynamic, where the body fluid balance throughout the day is determined by the fluid intake and the physiological process of water absorption, reabsorption, filtration, secretion and excretion, as well as physical activity, posture and body temperature.

The body hydrational status requiresmore than one test to provide accurate assess. Plasma osmolality, $\mathrm{P}_{\text {osm }}$ is one simple, safe, preciseand portable test recomended for this purpose(Armstrong et al., 2013).A few studies had shown that in subjects assigned to bed-rest, whether with or without supplementation; 
the plasma and urinary electrolytes such as sodium ( $\mathrm{Na}$ ), potassium $(\mathrm{K})$, calcium $(\mathrm{Ca})$ and magnesium $(\mathrm{Mg})$ excretion levels were significantly increased $(p \leq 0.05)$. The $\mathrm{P}_{\text {osm }}$, plasma protein level, whole blood hemoglobin $(\mathrm{Hb})$ and hematocrit $(\mathrm{Hct})$ level were also increased significantly $(p \leq 0.05)$ (Zorbas et al., 2002) However many studies agreed that $P_{\text {osm }}$ was one of the test which is consider as the gold standard to assess hydrational status (Minton and Eberman, 2009), (Armstrong et al., 2012).

The aim of this study is to assess the fluid intake and hydration status using several biochemical indices among the low risk postpartum women in Malaysia cultural setting, and to provide empirical evidences on the hydrational status among them to assess the risk of this group in developing VTE. It isa stepping stone in educating and counseling the lower risk women the importance of adequate fluid intake during their confinement period as part of post partum care.

\section{Methodology}

This study is a prospective longitudinal study over six month period, involving subjects attending maternity wards in Hospital Ampang, Selangor state of Malaysia.The study protocol was approved by the National Malaysian Research Registry (NMRR-16-1361-29016). Inclusion criteria included low risk postpartum women who consented to the study, uncomplicated antenatal records of singleton pregnancy and mothers who delivered via spontaneous vertex delivery. The initial calculated sample size with the power of $80 \%$ and $95 \%$ confidence interval was 200 . These women were recruited on day one post delivery. Their sociodemographic data, and baseline examination including measurements of biochemical analysis reflecting the hydrational status (plasma and urine osmolarity, plasma sodium, urea, creatinine and serum haemotocrit levels) were recorded. Patients were taught on how to selfmeasure their fluid input and output throughout their confinement phase in a specific diary. Subsequent follow up visit to reassess these parameters were made atthethird and sixth week post partum (Figure 1). Data were analysed with SPSS version 24.0. Demographic data were analysed descriptively while biochemical parameters were calculated statistically and repeated measures were analysed for significance $(p<0.05)$.

\section{Results}

Table 1: Descriptive demographic profile upon day 1 of recruitment, among low risk postpartum women delivered in Hospital Ampang. 


\begin{tabular}{|c|c|}
\hline Variables & Baseline $(\mathrm{N}=56)$ \\
\hline Age, mean (SD) & $27.96(4.46)$ \\
\hline \multicolumn{2}{|l|}{ Ethnic } \\
\hline Malay & $53(94.6 \%)$ \\
\hline Chinese & $1(1.8 \%)$ \\
\hline Others (Indonesian) & $2(3.6 \%)$ \\
\hline \multicolumn{2}{|l|}{ Education level } \\
\hline No formal education & $2(3.6 \%)$ \\
\hline Completed primary level & $2(3.6 \%)$ \\
\hline Completed secondary level & $24(42.9 \%)$ \\
\hline Completed tertiary level & $28(50.0 \%)$ \\
\hline \multicolumn{2}{|l|}{ Employment status } \\
\hline Working & $31(55.4 \%)$ \\
\hline Housewife & $25(44.6 \%)$ \\
\hline \multicolumn{2}{|l|}{ Parity } \\
\hline 1 & $19(33.9 \%)$ \\
\hline 2 & $19(33.9 \%)$ \\
\hline 3 & $13(23.2 \%)$ \\
\hline 4 & $4(7.1 \%)$ \\
\hline 5 & $1(1.8 \%)$ \\
\hline
\end{tabular}

A total of 56 subjects met the inclusion criteria. Majority of the patients (94.6\%) were from Malay ethnicity with mean age of $27.96 \pm 4.46$ years old and multiparaous, $66.1 \%(\mathrm{~N}=56)$. Half of the patients had completed tertiary level of education, while $42.9 \%$ had completed the secondary level. The majority $55.4 \%$ were working mothers while the remaining were housewives (44.6\%). (Table 1 )

The biochemical indices which reflect hydrational status among 56 postpartum low risk women were also analysed where the level on day 1 postpartum was taken as the baseline (day 1).The mean haematocrit was35.26\% (SD 4.09) which was normal (female normal range: 36 to 48\%). Median urea level at baseline was $2.10 \mathrm{mmol} / \mathrm{L}(\mathrm{SD} 3.00$ )(normal range: 1.8 to $7.1 \mathrm{mmol} / \mathrm{L}$ )andmean creatinine level 
was $45.6 \mu \mathrm{mol} / \mathrm{L}\left(\mathrm{SD} 8.82\right.$ )(normal range: 44 to $97 \mu \mathrm{mol} / \mathrm{L}$ ). Themean $\mathrm{P}_{\text {osm }}$ was 287.73 (SD 5.71) $\mathrm{mOsm} / \mathrm{kgand}$ the measured urine osmolality, $\mathrm{U}_{\mathrm{osm}}$ was 377.93 (SD 154.13) $\mathrm{mOsm} / \mathrm{kg}$. Calculated mean Urine specific gravity, $\mathrm{U}_{\mathrm{sg}}$ was 1.28 (SD 0.55).(Table 2 )

Subsequent measurements were taken and recorded at 3rd week and 6th week post partum. Only 15 respondent were able to complete all three visits with records of fluid input an output monitoring as well as completing all the hydrational status biochemical assessment. Results showed that the haematocrit levels were elevated by the 3rd week of postpartum [mean 39.06\% (SD 4.40)]and by6th weeks [mean $39.35 \%$ (SD 3.55]) with the median of $40.1 \%$ (SD 14.00). (Table 2)

Mean ureaat3rd weekpostpartum was $3.37 \mathrm{mmol} / \mathrm{L}(\mathrm{SD}$ 1.09) while the median creatinine was 59.00 $\mu \mathrm{mol} / \mathrm{L}(\mathrm{SD}$ 35.00). However these indices increased by 6 th week postpartum with mean urea level at3.81 $\mathrm{mmol} / \mathrm{L}\left(\mathrm{SD}\right.$ 0.97) and the mean creatinine level was; $59.93 \mu \mathrm{mol} / \mathrm{L}(\mathrm{SD} 9.04)$. These patients had $\mathrm{P}_{\text {osm }}$ of $297 \mathrm{mOsm} / \mathrm{kg}$ (SD 24.00)at 3rd week postpartum , while the mean $\mathrm{U}_{\text {osm }}$ was $652.46 \mathrm{mOsm} / \mathrm{kg}$ (SD $170.83)$ during the same period. The repeated measurement by $6^{\text {th }}$ week post partum revealedmean $P_{\text {osm }}$ almost unchanged, $297.33 \mathrm{mOsm} / \mathrm{kg}$ (SD3.55). Yet, the calculated mean $\mathrm{U}_{\mathrm{osm}}$ seems to be lesser at $6^{\text {th }}$ week, $644.46 \mathrm{mOsm} / \mathrm{kg}$ ( SD 241.93). (Table 2)

For the 15 women who completed the study, the measured $U_{s g}$ was1.28 (SD 0.55) at baseline and showed an increased pattern in the3rd week to2.18 (SD 0.59) and remained so by $6^{\text {th }}$ week postpartum, 2.17 (0.78). These women were also analysed on their cumulative fluid intake and output through the 3 rdand 6 th week postpartum. The median cumulative amount for total fluid intake at 3 week was much less than at 6 week; $1780 \mathrm{ml} /$ day per person as compared to $2130 \mathrm{ml} /$ day. The fluid output also showed similar pattern, at $3 \mathrm{rd}$ weeks it was $1083 \mathrm{ml} /$ day and increased a bit at $6^{\text {th }}$ week postpartum to $1216 \mathrm{ml} /$ day perperson. (Table 2)The measurable output was only through the urine output. Although the patients did document the frequency of bowel opening and breast feeding in the diary, unfortunately they were not able to quantify it to be analysed. (Table 3 )

Friedman Test was used to compare the differences of haematocrit, $\mathrm{P}_{\mathrm{osm}}$, urea and creatinine values between all 3 periods (baseline, 3rd week, 6th week). There was no significant changes on haematocrit values $(p=0.057)$. Urine specific gravity, $\mathrm{U}_{\mathrm{sg}}$ had significant increment $\left(\mathrm{p}<0.002^{\mathrm{a}}\right)$ from baseline to $3^{\text {rd }}$ week and $6^{\text {th }}$ week. (Table 3 )

On the other hand, as postpartum period progressed significant changes can be seen in $\mathrm{P}_{\text {osm }}(\mathrm{p}<0.001)$, urea $(p=0.001)$ and creatinine $(p=0.008)$ from baseline to $3^{\text {rd }}$ week and also from baseline to $6^{\text {th }}$ week postpartum. Post hoc Bonferroni analysis was done for urea level and showed significant increase level from baseline to $3^{\text {rd }}$ week $(p=0.009)$ and from baseline to $6^{\text {th }}$ week $(p=0.001)$. Similarly for creatinine, post hoc Bonferroni analysis showed a significant increase level between baseline and week $3(p=0.004)$ and between baseline and week $6(p=0.004) . P_{\text {osm }}$ were also analysed and showed a significant increase level 
between baseline and week $3(p=0.001)$, and between baseline and week $6(p=0.001)$ and significant between week 3 and week $6(p=0.008)$. (Table 3$)$.

Table 2: Description of biochemical values among low risk post partum women $(N=15)$ at baseline, $3^{\text {rd }}$ week and $6^{\text {th }}$ week.

\begin{tabular}{|c|c|c|c|c|}
\hline Variables $(\mathrm{N}=15)$ & & Baseline, Day 1 & Week 3 & Week 6 \\
\hline \multirow[t]{2}{*}{ Haematocrit (\%) } & Mean & \multirow[t]{2}{*}{$35.26(4.09)$} & \multirow[t]{2}{*}{$39.06(4.40)$} & $39.35(3.55)$ \\
\hline & Median & & & $40.10(14.00)$ \\
\hline \multirow[t]{2}{*}{ Urea (mmol/L) } & Mean & $2.37(0.81)$ & \multirow[t]{2}{*}{$3.37(1.09)$} & \multirow[t]{2}{*}{$3.81(0.97)$} \\
\hline & Median & $2.10(3.00)$ & & \\
\hline \multirow[t]{2}{*}{ Creatinine (umol/L) } & Mean & \multirow[t]{3}{*}{$45.60(8.82)$} & $60.26(10.68)$ & \multirow[t]{2}{*}{$59.93(9.04)$} \\
\hline & Median & & $\star 59.00(35.00)$ & \\
\hline \multirow[t]{2}{*}{ Convert creatinine $(\mathrm{mg} / \mathrm{dl})$} & & & $0.68(0.12)$ & \multirow[t]{2}{*}{$0.68(0.1)$} \\
\hline & & $0.52(0.1)$ & $\star 0.67(0.4)$ & \\
\hline Urea/ creatinine & & 4.56 & 5.02 & 5.60 \\
\hline \multicolumn{5}{|l|}{$(\mathrm{mmol} / \mathrm{L}) /(\mathrm{mg} / \mathrm{dl})$} \\
\hline \multirow[t]{2}{*}{ Plasma Osmolality (mOsm/kg) } & Mean & \multirow[t]{2}{*}{$287.73(5.71)$} & $300.93(7.37)$ & \multirow[t]{2}{*}{$297.33(3.55)$} \\
\hline & Median & & $297.00(24.00)$ & \\
\hline Urine Osmolality (mOsm/kg) & Mean & $377.93(154.13)$ & $652.46(170.83)$ & $644.46(241.93)$ \\
\hline Urine SG & Mean & $1.28(0.55)$ & $2.18(0.59)$ & $2.17(0.78)$ \\
\hline \multicolumn{5}{|l|}{ Cumulative fluid: } \\
\hline Input (ml/day) & Median & *NR & $1780(3350.5)$ & 2130(907.9) \\
\hline Output (ml/day) & Median & *NR & 1083 (969.6) & 1216(850.8) \\
\hline
\end{tabular}

*NR - not related as no fluid measurement taken upon day one post delivery. 
Table 3:Repeated Measures Analysis of biochemical values among low risk post partum women at baseline, week 3 and week 6, ( $N=15)$.

\begin{tabular}{|c|c|c|c|c|c|}
\hline Variables & Baseline & Week 3 & Week 6 & F-statistic & $\begin{array}{l}p- \\
\text { value }\end{array}$ \\
\hline \multirow[t]{2}{*}{$\begin{array}{l}\text { Haematocrit, mean } \\
\text { (SD) }\end{array}$} & \multirow[t]{2}{*}{$35.26(4.09)$} & \multirow[t]{2}{*}{$39.06(4.40)$} & $\begin{array}{l}\text { Mean: } 39.35 \\
(3.55)\end{array}$ & \multirow[t]{2}{*}{ - } & \multirow[t]{2}{*}{$0.057^{b}$} \\
\hline & & & $\begin{array}{l}\text { Median: } \\
40.10(14.00)\end{array}$ & & \\
\hline \multirow[t]{2}{*}{ Urea, mean (SD) } & $\begin{array}{l}\text { Mean: } 2.37 \\
(0.81)\end{array}$ & \multirow[t]{2}{*}{3.37 (1.09) } & \multirow[t]{2}{*}{$3.81(0.97)$} & \multirow[t]{2}{*}{ - } & \multirow[t]{2}{*}{$0.001^{\mathrm{b}}$} \\
\hline & $\begin{array}{l}\text { Median: } \\
2.10(3.00)\end{array}$ & & & & \\
\hline \multirow[t]{2}{*}{$\begin{array}{l}\text { Creatinine, mean } \\
\text { (SD) }\end{array}$} & \multirow[t]{2}{*}{$45.60(8.82)$} & $\begin{array}{l}\text { Mean: } 60.26 \\
(10.68)\end{array}$ & \multirow[t]{2}{*}{$59.93(9.04)$} & \multirow[t]{2}{*}{-} & \multirow[t]{2}{*}{$0.008^{b}$} \\
\hline & & $\begin{array}{l}\text { Median: } 59.00 \\
(35.00)\end{array}$ & & & \\
\hline \multirow[t]{2}{*}{$\begin{array}{l}\text { Plasma Osmolality, } \\
\text { mean (SD) }\end{array}$} & \multirow[t]{2}{*}{$\begin{array}{l}287.73 \\
(5.71)\end{array}$} & $\begin{array}{l}\text { Mean:300.93 } \\
(7.37)\end{array}$ & \multirow[t]{2}{*}{297.33 (3.55) } & \multirow[t]{2}{*}{-} & \multirow[t]{2}{*}{$\begin{array}{l}< \\
0.001^{1}\end{array}$} \\
\hline & & $\begin{array}{l}\text { Median: } \\
297.00 \text { (24.00) }\end{array}$ & & & \\
\hline $\begin{array}{l}\text { Urine Osmolality, } \\
\text { mean (SD) }\end{array}$ & $\begin{array}{l}377.93 \\
(154.13)\end{array}$ & $\begin{array}{l}652.46 \\
(170.83)\end{array}$ & $\begin{array}{l}644.46 \\
(241.93)\end{array}$ & $\begin{array}{l}F(1.026,14.365) \\
=13.926\end{array}$ & $0.002^{\mathrm{a}}$ \\
\hline $\begin{array}{l}\text { Urine SG, mean } \\
\text { (SD) }\end{array}$ & $1.28(0.55)$ & $2.18(0.59)$ & $2.17(0.78)$ & $\begin{array}{l}F(1.134,15.883) \\
=13.264\end{array}$ & $0.002^{\mathrm{a}}$ \\
\hline
\end{tabular}

${ }^{a} p$-value is significant at 0.05 using repeated measures ANOVA

${ }^{\mathrm{b}} p$-value is significant at 0.05 using Friedman test

\section{Discussion}

Out of 960 women who were screened for the low risk post partum mothersduring the six months duration of study only 56 met the inclusion criteria. Low risk postpartum women in this study included singleton pregnancy with uneventful antenatal history; delivered vaginally and with uncomplicated post delivery. The small sample size in this study is explained by the fact that being in low risk and considering themselves healthy, the majority were reluctant to to commit to a strict fluid monitoring as 
required in this study during the confinement period. They were also keen to undergo their confinement periodback in their hometown under the care of senior or close relatives care outside of the state. Only 15 women were able to complete the whole course of study till the end 6th week postpartum. Attritian rate was as high as $73 \%$, contributed by reluctancy to come for follow up visits since they were considered low risk, with no medical complaints that needed any medical attention. This is very much influnced by the cultural beliefs that since there were no medical problems it is best to complete the confinement phase in bound at home. Few cited transportation difficulties as reasons not to continue the study. Thus, due to these limitation, the baseline data comprised 56 patientswhile 15 of them completed all parameters of study measured at 3 different intervals.

The majority of our patients were of Malay ethnicity which reflects the demography composition in Malaysia where $61 \%$ of 32 million citizens are Malay (Statistic Department Malaysia). The majority of the Malay mothers still hold on to cultural practices during confinement period which include a strict regime of from food and fluid intake, having series of traditional massages and abiding to ample rest that is translated into immobility and forbiddance to go out of home, for at least 40 to 60 days post partum, with the good intention to ensure good recovery period for both mothers and babies(Koon et al., 2005). Regardless of the fact that the majority of mothers' mean age were within reproductive age and many were with multiple children (multiparous)indicating that they did have experience taking care of babies, the family and society support system usually will still ensure that a senior person take care of the mother and baby during this period. Malaysia is a modern developing country and the majority of women were well educated and have careers, yet, these do not stop them from adhering to the traditional practices as a way for recovery after birth ( $M, N$ and $E, 2018)$. The only things that may have changed were that services like massage therapy and confinement nurse have been commercialisedin recent decade with trained masseurs and midwives using battery operated massaging tools as well as modern sauna apparatus. However the principles in restricting food, fluid and mobilityare still highly observed.

The biochemical analyses for baseline group at day 1 post partum majority reflects normal values for hydrational status. The haematocrit were normal range as expected $35.26 \% \pm 4.09$ as these women were not anaemic and there were no post partum haemorrhages post deliveries.Haematocrit is a haematological indices that can resemble the hydrational status with the relation to risk of VTE. There was a study that reveled a multivariable hazard ratios per $5 \%$ increment of hematocrit for the total population which adjusted for age, body mass index and smoking were 1.25 (95\% Cl: 1.08-1.44) for total venous thromboembolism which is a risk factor in a general population (Braekkan et al., 2009). The mean haematocrit in 3rd week and median in 6th weeks increased in as much as $4-5 \%$ which may indicate mild dehydation had ensued despite no significant history of fluid loss recorded. Median was used instead of mean in some of the parameters due to skewness and not normally distributed in such a small sample. ANOVA did notshow anysignificant increment of haematocrit seenat 3rd and 6 th week $(\mathrm{p}=$ 0.057).

Blood urea and creatinine indicate the general status of renal function. Both are important in assessing the glomerular filteration rates which in turn is crucial in maintaining body fluid and electrolytes. Elevated 
urea more than creatinine in ratio, may indicate acute dehydration although it needs to be confirmed with clinical correlation.. Increased blood urea and creatinine ratio $(\mathrm{mmol} / \mathrm{L}) /(\mathrm{mg} / \mathrm{dl})>15$ (odds ratio [OR] 8.75)is an independent risk factor of developing venous thromboembolism in post acute ischaemic stroke(Kim et al., 2017). However urea is sensitive to dietary intake as it is the end product of protein and to physiological changes as compared to creatinine which is more stable in reflecting the renal function. Though urea is sensitive yet not specific, it is easily accessible and good in assessing general hydration status and renal function which explains its broad usage.. Our patients who were of low risk postpartum group, as expected showed normal hydration status and normal renal function at day 1 post delivery based on their urea and creatinine levels. However, repeated measurement analysis done at 3rd and 6th week post partum revealed significant increment of urea and creatinine level $\left(p=0.001^{b}\right.$ and $\left.p=0.008^{b}\right)$. Despite significant increment, the calculated ratio increased to not more than 15 . Thus, this indicated that our group of mothers a degree of less hydrated as compare to day 1 postpartum.

Plasma and urine osmolality are more reliable parameters in assessing hydrational status. They are subject to multiple factors especially when there are changes in the electrolytes and fluid intake itself (Armstrong et al., 2013). Yet, our patients who were all from low risk uncomplicated post partum group had normal electrolytes values hence ensuring that the calculated values of both plasma and urine osmolality in this study were unlikely to be influenced by electrolytes imbalance. Plasma osmolality, $\mathrm{P}_{\text {osm }}$ for adult generally ranges between $285-295 \mathrm{mOsm} / \mathrm{kg} \mathrm{H}_{2} \mathrm{O}$ while random urine osmolality, $\mathrm{U}_{\mathrm{osm}}$ normally ranges between 50-1200 mOsm/ $\mathrm{kg} \mathrm{H}_{2} \mathrm{O}$ (Tuazon, 2020). A twelveto 14-hour fluid restriction generally produces more than $850 \mathrm{mOsm} / \mathrm{kg} \mathrm{H}_{2} \mathrm{O}$ (SI units) $U_{\text {osm }}$ which suggests dehydration (Wilczynski, 2019). Plasma and urine osmolality are best compared together to get a better idea upon the hydrational status reflected by the kidney function.In our study, there was statistically significant increment of $\mathrm{P}_{\text {osm }}$ and $\mathrm{U}_{\text {osm }}$ between day 1 to 3 rd week and 6th week post partum (Fig. 3). Although the $\mathrm{U}_{\mathrm{osm}}$ did not reach the dehydrated level > $850 \mathrm{mOsm} / \mathrm{kg} \mathrm{H}_{2} \mathrm{O}$ (Wilczynski, 2019), $\mathrm{P}_{\mathrm{osm}}>296 \mathrm{mOsm} / \mathrm{kg}$ is considered a hyperosmolar state and is associated with high risk of mortality among acute stroke(Bhalla et al., 2000). It further support that these post partum women has been underhydartedduring the confinement phase.

Urine specific gravity, $\mathrm{U}_{\mathrm{sg}}$ is commonly used as general tool for hydration status too, as the specimen is easily collected in a simpler clinical setting i.e outpatient clinic. It is known to be sensitive but not specific. It has been compared with $\mathrm{P}_{\mathrm{osm}}$ and $\mathrm{U}_{\mathrm{osm}}$ for more accurate measurement of hydration among athletes. Yet, osmolality in both urine and plasma have better specificity in comparison. Nevertheless, our patient did have significant increment of $\mathrm{U}_{\mathrm{sg}}$ measurement $>1.010$ which may suggest mild dehydration, and similar with other parameters throughout the duration of 3 weeks of confinement and relatively the same from 3rd week to 6th week.

Study by $\mathrm{J}$ Kelly et al has shown that dehydration itself is a strong independent association with VTE in patients with acute post cerebrovascular event. It revealed that significant risk of VTE with increament of $\mathrm{P}_{\text {osm }}$, urea and also urea creatinine ratio(Kelly et al., 2004).Another study revealed that fluid, electrolyte and acid-base disorders had strong significant mutivariate analysis $(P<0.001)$ in risk of developing 
stroke and intracranial venous thrombosis post partum similar as cesarean delivery and hypertension during both peripartum and postpartum (Lanska and Kryscio, 2000).

Despite having a small cohort of sample, our study consistently revealed that the women with low postpartum risk, with limiting ambulation within their house but otherwise had normal dietry intake has been relatively dehydrated. There is no one specific biochemical measurement that able to quantify the hydration status accurately due to the dynamic process of the kidney, post partum hormonal recovery and breast feeding among these women. Yet, almost all the indices measured suggested of less hydrationalstate among them. Although these women had been complying to the advice to maintain adequate oral hydration, the calculated amount of fluid intake was rather low, slightly more than $1.5 \mathrm{~L} /$ day $(1.78 \mathrm{~L} /$ day at $3 r d$ week and $2.13 \mathrm{~L} /$ day) and the measured output were only $1 \mathrm{~L}$ to $1.2 \mathrm{~L}$ / day without calculating the insensible water loss( Fig. 2).The recommended amount of fluid intake for lactating mother is 3.1 liters equavalent to 13 cups perday, as compared to non-lactating mothers where the requirements are obviouslyless with 2.2 liters( 9 cups perday) and 2.3 liters (10 cups perday)("Dietary Reference Intakes for Water, Potassium, Sodium, Chloride, and Sulfate" at NAP.edu, 2004). Thus; our findings suggested that our local low risk nursing mothers are most likely under hydrated during the three to six weeks post partum. A study among Mexican women revealed fluid intakein between $2.62 \mathrm{~L}$ perday to $2.75 \mathrm{~L}$ perday during the first week of confinement. A large study in Indonesia with almost similar Asian cultural background showed that the fluid intake among the nursing mothers'during the first week postpartum were $2.3 \mathrm{~L}$ to $2.5 \mathrm{~L}$ perday. Although both study were studying the total of fluid and calorie intake in the first week post delivery among lactating mother with various socieeconomic background; both seems to have less fluid intake then recommended. Both studies did not have any hydration biochemical parameters assessed. Our data showed that the mothers' fluid intake was even lower which may predispose them to risk of dehydration and possible venous thromboembolism.

\section{Limitation}

It was rather challenging to recruit local women with low risk postpartum to commit with the prospective nature of this study that required series of visits. Despite the small sample size however, there were interesting statistically significant changes seen on the hydration parameters up to 3rd and 6th week post partum which correlated with the lower measured amount of fluid input. Perhaps a larger cohort of samples, from multicentre data where shorter distance between the home and research centre may provide promising results as it will improve subjects compliance to protocol. A comparison study between a controlled fluid intake and non control group may also provide better comparison for analysis.

Calculating the insensible water loss from passing motion and breast feeding may provide more accurate amount of water loss, which our study unable to quantify. Nevertheles this study is a stepping stone for a larger study in the impact of fluid intake on the hydration status. It is a good evidence that more measures are required to educate and enhance post partum care and fluid intake among post partum women in the local communities. 


\section{Conclusion}

This study aimed to evaluate the hydration status among low risk post partum women during the six week of confinement period within a Malaysian cultural setting. Despite a small cohort of samples there were statistically significant evidence of underhydration among these local women from the biochemical parameters taken namely the urea, creatinine, urine specific gravity, plasma and urine and osmolality. This was further supported by evidence of low fluid intake measured perday as compare to other studies and recommendation for nursing mother during confinement. Altough underhydrated, these women were not dehydrated and had normal electrolytes levels. However, this may predispose the low risk group to possible risk of developing venous thrombosis. Perhaps, a bigger cohort may provide better correlation between hydration and water intake to risk of developing venous thromboembolism. Nevertheless, this evidence is good enough to emphasize upon our low risk group of women to adequately consume fluids during confinement a ensure healthier mother, successful breast feeding and reduce risk of venous thrombosis.

\section{Abbreviations}

$P_{\text {osm }} \quad$ Plasma osmolality

SD standard deviation

$\mathrm{U}_{\text {osm }} \quad$ urine osmolality

$\mathrm{U}_{\mathrm{sg}} \quad$ urine specific gravity

VTE venous thrombosis event

\section{Declarations}

\section{Ethics approval and consent to participate}

Study approved by National Malaysian Research Registry (NMRR-16-1361-29016) for ethics and publication.

\section{Consent for publication}

Study approved by National Malaysian Research Registry (NMRR-16-1361-29016) for ethics and publication.

\section{Availability of data and material}

The datasets generated and analysed during the current study are not publicly available due personal information and policy by the university but are available from the corresponding author on reasonable 
request.

\section{Competing interests}

The authors have no competing interest.

\section{Funding}

Funding of this study by Universiti Sains Islam Malaysia PPP/USG-0215/FPSK/30/15815

\section{Authors' contributions}

All authors involved in study process, from proposal application, collecting samples, data entry, writing and reviewing the manuscript.

\section{Acknowledgements}

All the medical and nursing staff in Hospital Ampang, Malaysia whom are involve direct or indirectly during the study period.

\section{References}

Abdul Sultan, A., Grainge, M.J., West, J., Fleming, K.M., Nelson-Piercy, C. and Tata, L.J. (2014). Impact of risk factors on the timing of first postpartum venous thromboembolism: a population-based cohort study from England. Blood, [online] 124(18), pp.2872-2880. Available at:

https://www.ncbi.nlm.nih.gov/pmc/articles/PMC4215315/ [Accessed 28 May 2020].

Armstrong, L.E., Johnson, E.C., Munoz, C.X., Swokla, B., Bellego, L.L., Jimenez, L., Casa, D.J. and Maresh, C.M. (2012). Hydration Biomarkers and Dietary Fluid Consumption of Women. Journal of the Academy of Nutrition and Dietetics, [online] 112(7), pp.1056-1061. Available at: https://jandonline.org/article/S22122672(12)00471-6/pdf [Accessed 28 May 2020].

Armstrong, L.E., Maughan, R.J., Senay, L.C. and Shirreffs, S.M. (2013). Limitations to the use of plasma osmolality as a hydration biomarker. The American Journal of Clinical Nutrition, [online] 98(2), pp.503504. Available at: https://academic.oup.com/ajcn/article/98/2/503/4577271 [Accessed 17 May 2020].

Bardosono, S., Prasmusinto, D., Hadiati, D.R., Purwaka, B.T., Morin, C., Pohan, R., Sunardi, D., Chandra, D.N. and Guelinckx, I. (2016). Fluid Intake of Pregnant and Breastfeeding Women in Indonesia: A CrossSectional Survey with a Seven-Day Fluid Specific Record. Nutrients, [online] 8(11). Available at: https://www.ncbi.nlm.nih.gov/pmc/articles/PMC5133054/ [Accessed 28 May 2020]. 
Bhalla, A., Sankaralingam, S., Dundas, R., Swaminathan, R., Wolfe, C.D.A. and Rudd, A.G. (2000). Influence of Raised Plasma Osmolality on Clinical Outcome After Acute Stroke. Stroke, 31(9), pp.2043-2048.

Braekkan, S.K., Mathiesen, E.B., Njolstad, I., Wilsgaard, T. and Hansen, J.-B. (2009). Hematocrit and risk of venous thromboembolism in a general population. The Tromso study. Haematologica, [online] 95(2), pp.270-275. Available at: https://www.ncbi.nlm.nih.gov/pmc/articles/PMC2817030/pdf/0950270.pdf.

H, M. (2014). Fluid Consumption by Mexican Women During Pregnancy and First Semester of Lactation. [online] BioMed research international. Available at: https://pubmed.ncbi.nlm.nih.gov/24672791/ [Accessed 28 May 2020].

Heit, J.A., Kobbervig, C.E., James, A.H., Petterson, T.M., Bailey, K.R. and Melton, L.J. (2005). Trends in the Incidence of Venous Thromboembolism during Pregnancy or Postpartum: A 30-Year Population-Based Study. Annals of Internal Medicine, [online] 143(10), p.697. Available at:

https://www.acpjournals.org/doi/pdf/10.7326/0003-4819-143-10-200511150-00006 [Accessed 17 Oct. 2019].

Kamel, H., Navi, B.B., Sriram, N., Hovsepian, D.A., Devereux, R.B. and Elkind, M.S.V. (2014). Risk of a Thrombotic Event after the 6-Week Postpartum Period. New England Journal of Medicine, [online] 370(14), pp.1307-1315. Available at: https://www.nejm.org/doi/pdf/10.1056/NEJMoa1311485 [Accessed 28 May 2020].

Kelly, J., Hunt, B.J., Lewis, R.R., Swaminathan, R., Moody, A., Seed, P.T. and Rudd, A. (2004). Dehydration and venous thromboembolism after acute stroke. QJM: An International Journal of Medicine, 97(5), pp.293-296.

Kim, H., Lee, K., Choi, H.A., Samuel, S., Park, J.H. and Jo, K.W. (2017). Elevated Blood Urea Nitrogen/Creatinine Ratio Is Associated with Venous Thromboembolism in Patients with Acute Ischemic Stroke. Journal of Korean Neurosurgical Society, [online] 60(6), pp.620-626. Available at: https://www.ncbi.nlm.nih.gov/pmc/articles/PMC5678066/pdf/jkns-60-6-620.pdf [Accessed 17 May 2020].

Koon, P., Wong, Y., Peng, N. and Karim (2005). Postpartum Dietary Intakes and Food Taboos Among Chinese Women Attending Maternal and Child Health Clinics and Maternity Hospital, Kuala Lumpur. Mal $J$ Nutr, [online] 11(1), pp.1-21. Available at:

https://pdfs.semanticscholar.org/31c4/02312bb7d09290ce9eb31a8115e42670053f.pdf? _ga=2.47009891.519892745.1589880896-2050739426.1537343069.

Krishnan, M. (n.d.). Report on Confidential Enquiry into Maternal Death in Malaysia 2006-2008. [online] https://www.ogsm.org.my/docs/CEMD-report-2006-2008.pdf, MALAYSIA: Division of Family Health Development, Ministry of Health Malaysia, pp.1-200. Available at: https://www.ogsm.org.my/docs/CEMD-report-2006-2008.pdf [Accessed 27 May 2020]. 
Lanska, D.J. and Kryscio, R.J. (2000). Risk Factors for Peripartum and Postpartum Stroke and Intracranial Venous Thrombosis. Stroke, 31(6), pp.1274-1282.

Lewis, G. ed., (2011). Saving Mothers' Lives: Reviewing maternal deaths to make motherhood safer: 20062008. BJOG: An International Journal of Obstetrics \& Gynaecology, BJOG, pp.1-203.

M, W., N, K. and E, L. (2018). Traditional Beliefs and Practices in Pregnancy, Childbirth and Postpartum: A Review of the Evidence From Asian Countries. [online] Midwifery. Available at: https://pubmed.ncbi.nlm.nih.gov/29132060/.

Minton, D.M. and Eberman, L.E. (2009). Best Practice for Clinical Hydration Measurement. Athletic Therapy Today, [online] 14(1), pp.9-11. Available at: https://journals.humankinetics.com/view/journals/ijatt/14/1/article-p9.xml [Accessed 20 Jul. 2019].

POMP, E.R., LENSELINK, A.M., ROSENDAAL, F.R. and DOGGEN, C.J.M. (2008). Pregnancy, the postpartum period and prothrombotic defects: risk of venous thrombosis in the MEGA study. Journal of Thrombosis and Haemostasis, [online] 6(4), pp.632-637. Available at:

https://onlinelibrary.wiley.com/doi/epdf/10.1111/j.1538-7836.2008.02921.x [Accessed 28 May 2020].

Read "Dietary Reference Intakes for Water, Potassium, Sodium, Chloride, and Sulfate" at NAP.edu. (2004). [online] www.nap.edu. Institute of Medicine, Washington, DC, National Academy Press. Available at: https://www.nap.edu/read/10925/chapter/6? term=median+amount+of+fluids+typically+consumed+by+breastfeeding+mothers+is+3.1+liters+\#153 [Accessed 19 May 2020].

Reducing the Risk of Venous Thromboembolism during Pregnancy and the Puerperium. (2015). Available at: https://www.rcog.org.uk/globalassets/documents/guidelines/gtg-37a.pdf [Accessed 27 May 2020].

Sommerfield, L.M., McAnulty, S.R., McBride, J.M., Zwetsloot, J.J., Austin, M.D., Mehlhorn, J.D., Calhoun, M.C., Young, J.O., Haines, T.L. and Utter, A.C. (2016). Validity of Urine Specific Gravity When Compared With Plasma Osmolality as a Measure of Hydration Status in Male and Female NCAA Collegiate Athletes. Journal of Strength and Conditioning Research, [online] 30(8), pp.2219-2225. Available at: https://www.ncbi.nlm.nih.gov/pmc/articles/PMC4912946/ [Accessed 4 Dec. 2019].

Tuazon, S.A. (2020). Serum Osmolality: Reference Range, Interpretation, Collection and Panels. [online] eMedicine. Available at: https://emedicine.medscape.com/article/2099042-overview [Accessed 17 May 2020].

Wilczynski, C. (2019). Urine Osmolality: Reference Range, Interpretation, Collection and Panels. [online] Medscape.com. Available at: https://emedicine.medscape.com/article/2088250-overview.

Zorbas, Y.G., Kakurin, V.J., Kuznetsov, N.A. and Yarullin, V.L. (2002). Fluid and salt supplementation effect on body hydration and electrolyte homeostasis during bed rest and ambulation. Acta astronautica, 
[online] 50(12), pp.765-74. Available at: https://www.ncbi.nlm.nih.gov/pubmed/12053941 [Accessed 3 Dec. 2019]

\section{Figures}

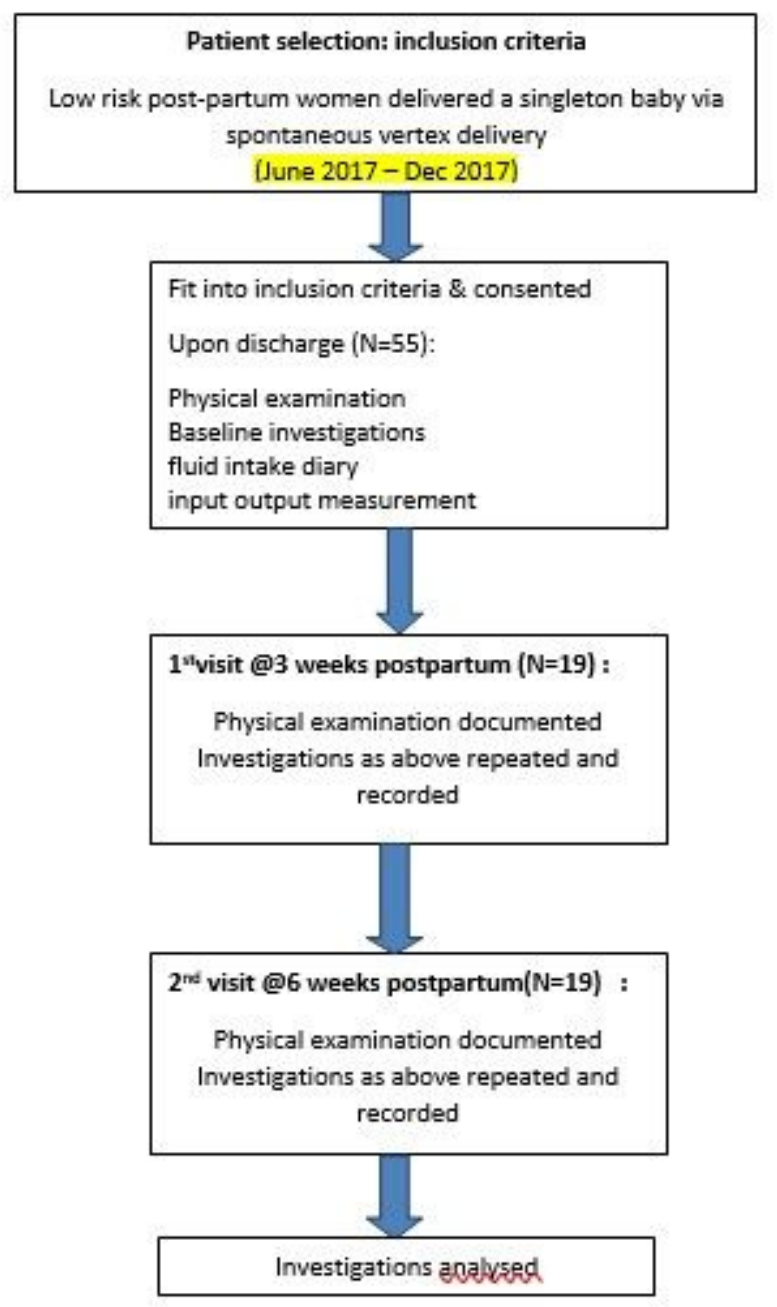

\section{Figure 1}

Study Flowchart for Recruitement and Followup Visits 